MON2B-3

\title{
MONOLITHIC POWER AMPLIFIERS COVERING 70-113 GHZ
}

\author{
H. Wang ${ }^{\star}$, L. Samoska ${ }^{+}$, T. Gaier ${ }^{+}$, A. Peralta ${ }^{+}$, \\ H. H. Liao , Y. C. Chen \\ *Dept. of Electrical Engineering and Graduate Institute of Communication Engineering, \\ National Taiwan University, Taipei, Taiwan, 10617, ROC \\ ${ }^{+}$Jet Propulsion Laboratory, \\ 4800 Oak Grove Drive, Pasadena, CA 91149, USA \\ ${ }^{*}$ TRW, Space and Electronics Group, \\ One Space Park, Redondo Beach, CA 90278, USA
}

\begin{abstract}
A number of monolithic W-band power amplifiers (PAs) have been developed for local oscillators of the Far Infrared and Submillimeter Telescope (FIRST). These PA chips include three driver and three power amplifiers covering most of the W-band, i.c., the frequency ranges of 72-81, 90-101, and 100$113 \mathrm{GHz}$. Each driver amplifier and power amplifier provides at least 20 and $22 \mathrm{dBm}(160$ $\mathrm{mW}$ ), respectively in the frequency range it covers. The 100-113 $\mathrm{GHz}$ power amplifier has a peak power of greater than $250 \mathrm{~mW}(25$ dBm) at $105 \mathrm{GHz}$, which is the best output power performance for a monolithic amplifier above $100 \mathrm{GHz}$ to date. These monolithic chips are fabricated using $0.1-\mu \mathrm{m}$ AlGaAs/InGaAs/GaAs pseudomorphic T-gate power HEMTs on a 2-mil GaAs substrate.
\end{abstract}

\section{INTRODUCTION}

W-band MMIC power amplifiers (PAs) have been developed for transmitter applications [1]-[2]. These amplifiers can be used as drivers for local oscillator (LO) sources at frequencies into the $\mathrm{THz}$ range. The local oscillators for the Far-Infrared and Sub-millimeter Telescope (FIRST) will be comprised of synthesizers and active multipliers to provide output frequencies of 71-112.5 GHz, PAs to amplify these W-band signals, and finally chains of Schottky diode multipliers to achieve $\mathrm{THz}$ frequencies. The motivation of this work is to develop a chip set of W-band MMIC PAs which could be used for the FIRST LO chains.

This paper will present the results of these W-band MMIC PA chips. The chips are fabricated using $0.1-\mu \mathrm{m}$ AlGaAs/InGaAs/GaAs pseudomorphic (PM) T-gate power HEMT MMIC technology on a 2-mil GaAs substrate. Although InP-based HEMT MMICs have demonstrated excellent power performance at Wband [2], GaAs-based HEMT MMIC technology was selected for this project due to the process maturity. The 2-mil GaAs HEMT PAs not only demonstrated good power performance with high yield at W-band $(94 \mathrm{GHz})$ [1], but also showed impressive results from $\mathrm{Ka}$ - to $\mathrm{V}$-band [3]-[6]. In this work, three sets of $\mathrm{PA}$ chips and their driver amplifiers covering 72-81, 90-101, and 100-113 $\mathrm{GHz}$ were designed, fabricated and tested. The three driver amplifiers were designed with a common output gate periphery of $640 \mu \mathrm{m}$, while the PAs had $1280 \mu \mathrm{m}$, to fulfill output power requirements. The measurement results indicated each driver amplifier and power amplifier provide at least 20 and $22 \mathrm{dBm}(160 \mathrm{~mW})$, respectively, in the frequency range which it 
covered. For the first time, the full power data as a function of frequency are presented in W-band and the wide-band capability is demonstrated. Moreover, the $100-113 \mathrm{GHz}$ power amplifier has a peak power of greater than $250 \mathrm{~mW}(25 \mathrm{dBm})$ at $105 \mathrm{GHz}$, which is the best output power performance for a monolithic amplifier above 100 $\mathrm{GHz}$ to date.

\section{MMIC PROCESS AND DEVICE CHRACTERISTICS}

The $0.1-\mu \mathrm{m}$ power HEMT device development has been reported [7]. The HEMT structure is grown using molecular beam epitaxy (MBE) on three-inch substrates and uses a PM $\mathrm{I}_{0.22} \mathrm{Ga}_{0.78}$ As channel. The HEMT device structure is based on a double heterostructure design to achieve a high aspect ratio for $0.1-\mu \mathrm{m}$ gate lengths. The devices typically exhibit a gateto-drain breakdown voltage of $6 \mathrm{~V}$ measured at a gate current of $0.1 \mathrm{~mA} / \mathrm{mm}$, a peak dc transconductance of $600 \mathrm{mS} / \mathrm{mm}$, a maximum current of $600 \mathrm{~mA} / \mathrm{mm}$, a unit current gain frequency $f_{\mathrm{T}}$ of $130 \mathrm{GHz}$, and a maximum oscillation frequency $f_{\max }$ of greater than $200 \mathrm{GHz}$.

\section{HEMT DEVICE MODELING AND CIRCUIT DESIGN}

The HEMT linear small signal equivalent circuit parameters are obtained from careful fit of the measured small signal S-parameters to 50 $\mathrm{GHz}$. These parameters are consistent with an estimation based on device physical dimensions and parameters. The Curtice-Ettenberg FET asymmetric model was used to describe the HEMT device nonlinear behavior [8]. The nonlinear transconductance coefficients were then obtained from fitting the dc-IV measurement of the devices. The device models have been verified by comparing the measured and simulate on results of simple pre-matched device structures [1].

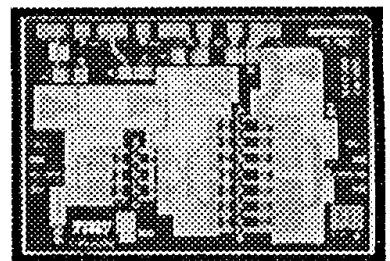

(a)

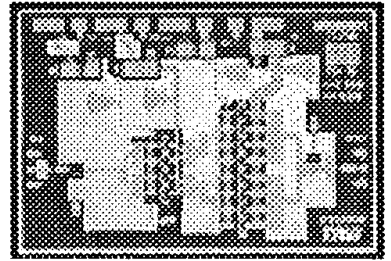

(b)

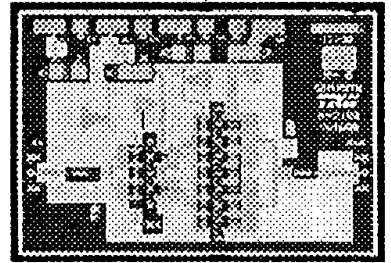

(c)

Fig. 1. The photographs of the three $\mathrm{W}$-band monolithic PAs: (a) $72-81$, (b) $90-101$, and (c) $100-113 \mathrm{GHz}$. The chip sizes are $2.3 \times 1.6 \mathrm{~mm}^{2}$.

Fig. 1 shows the three PA chips (covering 72-81, 90-101, and 100-113 GHz). All the three PAs follow a common circuit architecture, which is a single-ended two-stage design. The first stage employs four cells of 8-finger, $160-\mu \mathrm{m}$ HEMT devices and second stage has twice the device periphery with eight HEMT devices. The topology used for the PA designs has been reported in [1]. For these new designs, reactive matching elements were optimized for increased bandwidth and higher frequency performance. EM simulations were performed for all the passive structures using Sonnet [9]. The driver amplifiers also follow a common circuit architecture, which is similar to that of the PAs with half of the gate peripheries for both the first and second stages. 


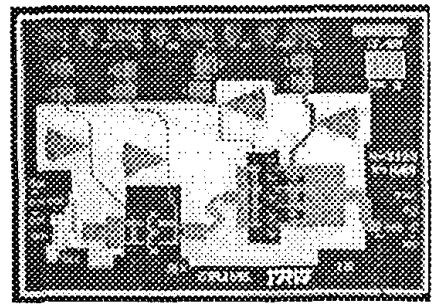

(a)

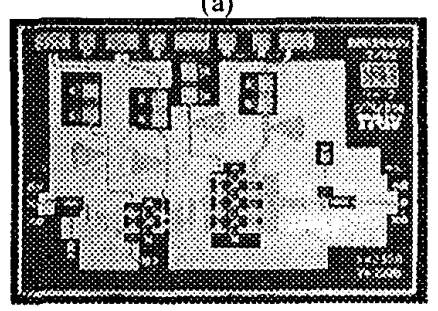

(b)

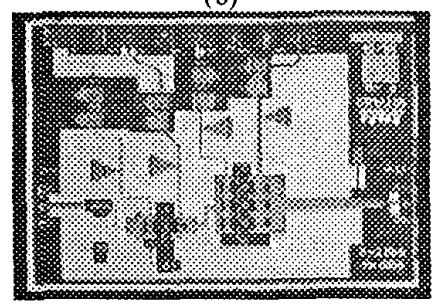

(c)

Fig. 2. The photographs of the three $W$-band drive amplifiers: (a) $72-81$, (b) $90-101$, and (c) $100-113 \mathrm{GHz}$.

Fig. 2 shows the chip photographs of the three driver amplifiers. The chip sizes for all of the amplifiers are $2.3 \times 1.6 \mathrm{~mm}^{2}$, in order to facilitate ease of dicing of the wafers.

\section{MEASUREMENT RESULTS}

The PAs and driver amplifiers were first tested for gain using on-wafer small signal measurements. A measured typical small signal gain of at least 8,7 and $4 \mathrm{~dB}$ is achieved at 72 $81,90-101$, and $100-113 \mathrm{GHz}$, respectively at a drain voltage $\left(V_{d}\right)$ of $1.5 \mathrm{~V}$ with gate voltage set to $0 \mathrm{~V}$ for the three PAs as shown in Fig. 3(a). The three microstrip driver amplifiers depict high gain performance of 12,7 , and $7 \mathrm{~dB}$ as shown in Fig. 3(b). The chips were then diced and tested in a WR-10 waveguide module (with a pair of

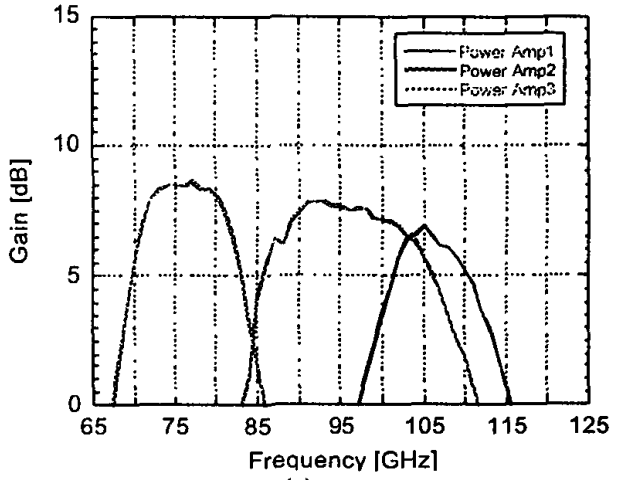

(a)

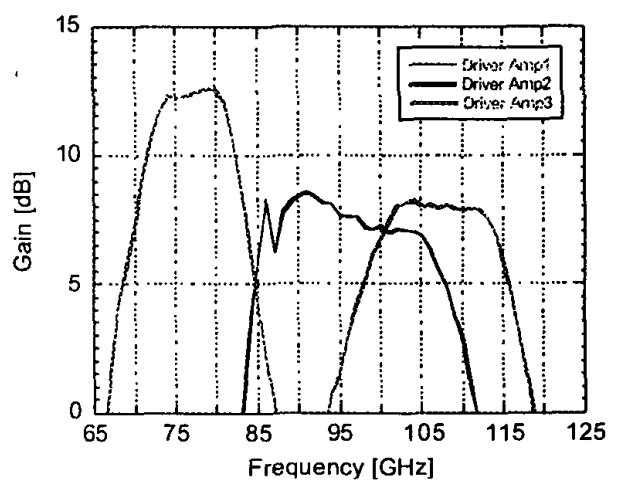

(b)

Fig. 3. The measured on-wafer small signal gain vs. frequency of the three W-band (a) PAs, and (b) driver amplifiers.

microstrip-line to waveguide transitions [10]) for small signal response and output power.

Power measurements were performed at $V_{d}=2.5 \mathrm{~V}$ to maximize output power and bandwidth of the chips. The driver amplifiers showed up to $100 \mathrm{~mW}$ of peak output power, and the power amplifiers typically exhibited $200 \mathrm{~mW}$ of output power. The amplifier modules were then cascaded in order of increasing output stage gate periphery: the driver $(640 \mu \mathrm{m})$ was followed by a power amplifier $(1.28 \mathrm{~mm})$. Fig. 4 shows the maximum output power performance vs. frequency at the output of the cascaded modules. Three frequency bands are covered in three separate pairs of modules. Each amplifier chain 


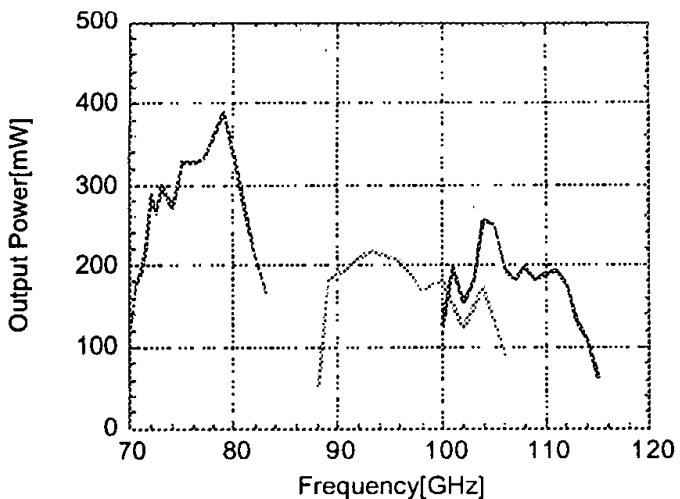

Fig. 4. The output power vs. frequency plot of the three W-band packaged power amplifiers.

demonstrated at least $22 \mathrm{dBm}(158 \mathrm{~mW})$ in the frequency range it covers. The $100-113 \mathrm{GHz}$ power amplifier has a peak power of greater than $250 \mathrm{~mW}(25 \mathrm{dBm})$ at $105 \mathrm{GHz}$, which is the best output power performance for a monolithic amplifier above $100 \mathrm{GHz}$ to date. It is also noted that the waveguide transition has an insertion loss of $0.35 \mathrm{~dB}$ up to $107 \mathrm{GHz}$, and $0.5 \mathrm{~dB}$ from 107 . $115 \mathrm{GHz}$ [10]. For the output power results at the MMIC chip end, the numbers mentioned above need to be corrected by this loss factor.

\section{SUMMARY}

We have presented a chip set of monolithic W-band power amplifiers using 2-mil $0.1-\mu \mathrm{m}$ AlGaAs/InGaAs/GaAs PM T-gate power HEMT MMIC production process technology for LO sources which are useful for astronomical telescope applications. Measurement results show that at least $22-\mathrm{dBm}$ output power can be provided for the frequency bands of 72-81,90101 , and $100-113 \mathrm{GHz}$. The $100-113 \mathrm{GHz} P A$ and driver amplifiers are the first reported MMIC PAs above $100 \mathrm{GHz}$.

\section{ACKNOWLEDGEMENT}

The authors would like to thank P.P Huang for the PA design consultation and the members of the RF Product Center of TRW for their technical support. This work was carried out in part by the Jet Propulsion Lab, California Institute of
Technology, under a contract with the National Aeronautics and Space Administration.

\section{REFERENCES}

[1] P. P. Huang, T. W. Huang, H. Wang, E. Lin, Y. H. Shu, G. S. Dow, R. Lai, M. Biedenbender, and J. Elliot, "A Wband $0.35-W$ power amplifier module," IEEE Trans. on Microwave Theory and Tech., vol. 45, no. 12, part 2, pp. 2418-2423, Dec., 1997.

Y. C. Chen, D. L. Ingram, R. Lai, M. Barsky, R. Grunbacher, T. Block, H. C. Yen and D. C. Streit, "A 95GHz InP HEMT MMIC amplifier with 427-mW power output," IEEE Microwave and Guided Wave Lett., vol. 8, no. 11,pp. 399-401, Nov., 1998.

[3] D. L. Ingram, D. I. Stone, H. Wang, J. H. Elliot, R. Lai, and M. Biedenbender, "A 6 watt Ka-band power module using MMIC power amplifiers," IEEE Trans. on Microwave Theory and Tech., vol. 45, no. 12, part 2, pp. 2424 -2430, Dec., 1997.

[4] J. A. Lester et al., "Highly efficient compact Q-band MMIC power amplifier using 2-mil substrate and partially-matched output," 1996 IEEE MTT-S Int. Microwave Symp. Dig., San Francisco, CA, vol. 1, pp.153-155, June, 1996.

[5] Y. Hwang, J. Lester, G. Schreyer, G. Zell, S. Schrier, D. Yamauchi, G. Onak, B. Kasody, R. Kono, Y. C. Chen, and R. Lai, "60 GHz high efficiency HEMT MMIC chip set development for high power solid state power amplifier," 1997 IEEE MTT-S Int. Microwave Symp. Dig., Denver, Co, vol. 3, pp.1179-1182, June, 1997.

[6] O. S. A. Tang, K. H. G. Duh, S. M. J. Liu, P. M. Smith, W. F. Kopp, T. J. Rogers and D. J. Pritchard, "A $560 \mathrm{~mW}$, $21 \%$ power-added efficiency V-band MMIC power amplifier," 18th Annual IEEE GaAs IC Symposium Digest, Orlando, FL, Nov., 1996.

[7] M. Biedenbender, R. Lai, J. Lee, S. Chen, K. L. Tan, P. H. Liu, D. C. Streit, B. Allen, and H. Wang, "A $0.1 \mu \mathrm{m} \mathrm{W-}$ band HEMT production process for high yield and high performance low noise and power MMICs," 16th Annual IEEE GaAs IC Symposium Digest, pp. 323-327, Philadelphia, PA. Oct., 1994.

[8] W. R. Curtice and M. Ettenberg, "A nonlinear GaAs FET model for use in the design of output circuits for power amplifiers," IEEE Trans. Microwave Theory Tech, vol. MTT-33, pp. 1383-1394, Dec. 1985.

[9] EM user's Manual, Release 3.0, Sonnet Software Inc., Liverpool, NY, June, 1995.

[10] Y. C. Leong and S. Weinreb, "Full band waveguideto-microstrip probe transitions," 1999 MTT-S International Microwave Symposium Digest, vol. 4, pp. 1435-1438, Anaheim, CA, June, 1999. 